\title{
ROLE OF ASCITIC FLUID STUDY IN EARLY DETECTION OF SPONTANEOUS BACTERIAL PERITONITIS IN ASYMPTOMATIC PATIENTS OF CIRRHOSIS OF LIVER
}

\author{
MD. ASADUL KABIR ${ }^{1}$, MD. MANIRUZZAMAN SARKAR ${ }^{2}$, KAZI BODRUDDOZA $^{3}$, ANWARUL BARI ${ }^{4}$, JEWEL \\ CHOWDHURY ${ }^{5}$
}

\begin{abstract}
Spontaneous bacterial peritonitis (SBP)is an acute bacterial infection of ascitic fluid and one of the commonest complication of patients with cirrhosis presented with ascitis. Routine analysis of ascetic fluid particularly for polymorphonuclear leukocyte is an important tool for detecting spontaneous bacterial peritonitis including clinically unsuspected and asymptomatic patients also. Thus it helps in reducing mortality and morbidity by early and effective detection of spontaneous bacterial peritonitis.
\end{abstract}

Objective: This study was carried out to evaluate the role of ascitic fluid analysis in early detection of spontaneous bacterial peritonitis and to document the proportion of spontaneous bacterial peritonitis present asymptomatically.

Study design: This was a cross sectional observational study prospective in nature on 50 cases of diagnosed chronic liver disease patients in indoor of department of medicine of Sir Salimullah medical college Hospital, Dhaka from 02/01/13 to 01/07/13, for a period of 6 months.

\begin{abstract}
Result: The study showed that age frequency 5(10\%) were from 21-30 years, 15(30\%) were from 3140 years, $15(30 \%)$ were from $40-50$ years and $15(30 \%)$ were from $>50$ years of age. Out of 50 patients, 38(76\%) were male and 12(24\%) were female patients. The etiology of liver cirrhosis was hepatitis $B$ virus in 22(44\%), hepatitis $C$ virus in 4(8\%), alcohol in 1 (2\%) and others in 23(46\%) patients. Among 50 patients, 16(32\%) were spontaneous bacterial peritonitis and 34(68\%) were non spontaneous bacterial peritonitis. The symptoms of spontaneous bacterial peritonitis were upper GI bleeding in 8 patients (50\%), fever in 12 patients (75\%), abdominal pain in 10 patients (62.5\%), abdominal tenderness in 7 patients (43.75\%), hepatic encephalopathy in 9 patients (56.25\%), jaundice in 10 patients (62.50\%), splenomegaly in 16 patients (100\%), ascites in 16 patients (100\%) and 5 (10\%) patients were asymptomatic spontaneous bacterial peritonitis. According to Child Pugh's, 2(12.5\%) patients were at stage- $A, 5$ (31.25\%) patients were at stage- $B$ and 9 (56.25\%) patients were at stageC. Ascitic fluid characteristics (mean $+S D$ ) of all patients were, Total cell counts $/ \mathrm{mm}^{3}(571+499.9)$, Neutrophil counts $/ \mathrm{mm}^{3}$ (144.8+445.1), Sugar (112+38.19) mg/dl, Protein (1.85+1.09). Among SBP patients, 7 (43.75\%) have PMN cell counts $250-750 / \mathrm{mm}^{3}$, $6(37.50 \%)$ have $750-1750 / \mathrm{mm}^{3}$ and 3 (18.75\%) have $>1750 / \mathrm{mm}^{3}$.
\end{abstract}

Conclusion: Spontaneous bacterial peritonitis is a common complication of decompensated cirrhotic patients. The classical signs of SBP (e.g. abdominal tenderness or fever) may not be present. We observed the trend towards more frequent occurrence of the infection in patients suffered from severe liver disease (e.g. Child Pugh's $-C$ ) and the role of ascitic fluid analysis is statically significant.

Received: 03 September 2018

Accepted: 05 November 2018

DOI: https://doi.org/10.3329/bjmed.v30i1.39917

1. Associate Professor, Department of Medicine, SSMC \& MH, Dhaka.

2. Assistant Registrar, Department of Gastroenterology, Rangpur Medical College Hospital.

3. Honorary Medical Officer, Medicine Unit - VII, SSMC \& MH, Dhaka.

4. Associate Professor, Department of Medicine, SSMC \& MH, Dhaka.

5. Registrar, Department of Medicine, SSMC \& MH, Dhaka.

Address of Correspondence: Dr. Associate Professor, Department of Medicine, SSMC \& MH, Dhaka.

Bangladesh J Medicine 2019; 30 : 9-18 


\section{Background}

Chronic hepatitis represents a series of liver disorders of varying causes and severity in which hepatic inflammation and necrosis continue for at least six months. Milder form are non-progressive or only slowly progressive, while more severe forms may be associated with scarring and architectural reorganization, which, when advanced, lead ultimately to cirrhosis. ${ }^{1}$

Cirrhosis is a consequence of chronic liver disease characterized by replacement of liver tissue by fibrosis, scar tissue and regenerative nodules. Fibrosis is a part of the innate wound healing response that occurs in injured tissue. Within the liver, fibrosis is characterized by the deposition of extracellular matrix. The progression of fibrosis to cirrhosis has a number of sequelae. First, it will distort hepatic architecture and vasculature; second, it will have a deleterious effect on hepatic function; and third, it will increase the propensity of hepatic neoplastic transformation.

Therefore the evolution of fibrosis to cirrhosis represents a change in the morphology, hemodynamic and functions of the liver. The definition of cirrhosis remains morphological, described by working party for the World Health Organization in 1978 as: ' a diffuse process characterized by fibrosis and the conversion of normal liver architecture into structurally abnormal nodules'.2

Anatomical (morphological) diagnosis of cirrhosis depends on demonstrating wide spread nodules in the liver combined with fibrosis. Cirrhosis may be micro nodular, macro nodular or mixed.

In clinical terms, cirrhosis is described as either "compensated" or "decompensated". Decompensation means cirrhosis complicated by one or more of the following features: Jaundice, ascites, hepatic encephalopathy, bleeding varices. Ascites is the usual first sign. Hepatorenal syndrome, hyponatremia, spontaneous bacterial peritonitis is also features of decompensation but in these patients ascites invariably occurs first. Compensated cirrhotic patients have none of these features.

This is very important clinical distinction and has major implication for prognosis and treatment. Compensated cirrhotic patients have a 50\% 10-years survival as compared to $50 \%$ survival at 18 months for decompensated patients. Cirrhotic patients become decompensated at the rate of approximately $10 \%$ per year. ${ }^{3}$

Ascites is a major complication of cirrhosis ${ }^{4}$, occurring in $50 \%$ of patients over ten years of follow-up ${ }^{5}$. The development of ascites is an important landmark in the natural history of cirrhosis ${ }^{5,6}$. In most study, ascites was the first complication to occur and to mark decompensation of liver disease ${ }^{6,7}$. Bacterial infections are a common and recurrent complication of cirrhosis associate with poor outcome ${ }^{8}$. The most common infections in cirrhotic patients are spontaneous bacterial peritonitis (SBP) (25\%), followed by urinary tract infection $(20 \%)$, Pneumonia(15\%), bacteraemia following a therapeutic procedure, cellulites ${ }^{8}$.

SBP is a frequent and severe complication of decompansated cirrhosis. Approximately half the episodes of SBP are present at the time of hospital admission and the remainder is acquired during hospitalization ${ }^{9}$. The percentage of SBP in hospitalized cirrhotic patient with ascites ranges between 10\%$30 \%{ }^{10-13}$ In most recent prospective study, the mortality rate was reported to be around $20 \%{ }^{9,14}$.

Conn first introduce the term SBP, publishing his clinical findings just one year after Kerr et al., describe (in 1963) 11 cases of seemingly unexplained infection of the ascetic fluid. ${ }^{15}$

SBP defined as the infection of ascitic fluid without a contagious source of intra-abdominal infection (e.g. intra-abdominal abscess, intestinal perforation) and in the absence of intra-abdominal focus of inflammation, cholecystitis or acute pancreatitis. ${ }^{16}$

The presentation of SBP recently observed in a consecutive series of hospitalize patient ${ }^{17}$ are fever, abdominal pain, hepatic encephalopathy, renal failure, blood leucocytosis. Patient with SBP are frequently asymptomatic $^{18}$ or minor symptoms only, this is particularly so when the diagnosis of infection is made at hospital admission. ${ }^{19}$

So diagnosis of SBP established on the basis of symptoms and signs is not acceptable. ${ }^{19}$

A diagnostic paracentesis should be performed on all hospitalized cirrhotic patient with ascites (whether Symptoms or signs of SBP are present or not) to investigate the presence of SBP. ${ }^{19}$ As SBP is a serious complication of cirrhosis, treatment cannot be delayed until microbiological results are available. Therefore, empirical antibiotic treatment for SBP is started when objective evidence of a local inflammatory reaction is present, i.e. an elevated ascitic fluid poly morphoneuclear neutrophil (PMN) cell count.19

On the basis of currently available data, the greatest sensitivity for the diagnosis of SBP is reached with a cut off PMN cell count of $250 / \mathrm{mm} 3$, although the greatest specificity is reached with a cut off at 500 $\mathrm{PMN} / \mathrm{mm} 3.20,21,22$ However, since it is important not to miss a case of SBP, the most sensitive cut-off value (PMN $>250 / \mathrm{mm} 3)$ is used. 
In patients with bloody ascitic fluid (i.e. ascitic fluid red blood cell count $>10,000 / \mathrm{mm} 3$, as the result of traumatic tap or conditions causing hemorrhagic ascites (e.g. Neoplasm) ${ }^{23}$, a correction factor of one PMN cell per 250 RBC (red blood cell) has been proposed, since this is the maximum expected ratio of PMN to RBCs normally present in peripheral blood. ${ }^{23}$

Although some physician still established the diagnosis of spontaneous bacterial peritonitis( SBP) on the basis of both the ascetic fluid total leucocytes count (TLC) and the percentage of PMNs, there is no rationale for the use of this criterion in the diagnosis of SBP. ${ }^{20,24}$

\section{Literature Review}

Cirrhosis is the end stage of every chronic liver disease, resulting in formation of fibrous tissue, disorganization of liver architecture and nodule formation, which interferes with liver function and results in portal hypertension. Portal hypertension is associated with development of a hyper dynamic circulation and complications such as ascites, hepatic encephalopathy and oesophago-gastric varices. ${ }^{32}$

In most study, ascites was the first complication to occur and to mark decompensation of liver disease. ${ }^{6,7}$ Cirrhotic patients with ascites are particularly susceptible to SBP due to altered gut permeability, suppression of reticuloendothelial system and bacterial over growth. ${ }^{33,34}$

Bacterial infections are a common and recurrent complication of cirrhosis associate with poor outcome. ${ }^{8}$ The most common infections in cirrhotic patients are SBP $(25 \%)$, followed by urinary tract infection (20\%), Pneumonia(15\%), bacteremia following a therapeutic procedure, cellulites. ${ }^{8}$.

SBP is a frequent and severe complication of decompensated cirrhosis. Approximately half the episodes of SBP are present at the time of hospital admission and the remainder is acquired during hospitalization. ${ }^{9}$ It is pointed out in the literature that the percentage of SBP in hospitalized cirrhotic patient with ascites ranges between 10\%-30\%. ${ }^{10-13}$

A descriptive, cross sectional study was conducted by Zahidullah Khan et al. ${ }^{35}$ in medical units of Khyber Teaching Hospital, Peshawar from July, 2008 to Jan, 2009, have shown that the overall frequency of SBP in cirrhotic patients with ascites was $38 \%$.

MP Agarwal et al. ${ }^{36}$ was conducted a study that shown the prevalence of SBP 34.14\%. The reason for a higher prevalence in that study was mentioned that there were comparatively more patients in Child Pugh class C, those are more prone to develop ascitic fluid infection.
Ali Sakib et al. ${ }^{37}$ showed frequency of SBP was $31 \%$ that correlates with further Pakistani study by Imran et al. (38) (Showed 31.58\%). Ali Sakib et al. ${ }^{37}$ explained the higher prevalence by the late presentation of the patients to the tertiary care hospital in their indigenous set up, advanced stage of disease at presentation, poor socioeconomic condition, under nutrition with weak immune system and noncompliance to the therapy.

Furthermore, from India in 1999 Jain A P et al. ${ }^{39}$ showed prevalence of $34.92 \%$. Syed VA et al. ${ }^{40}$ had prospectively evaluated 81 cirrhotic patients with ascites during one year period and showed prevalence of SBP $24.67 \%$.

SBP clinically presents both symptomatically and asymptomatically. Criteria for defining SBP are ${ }^{41,42}$ : 1. Temperature $>38^{\circ} \mathrm{C}$ or $<36.5,2$. Chills, 3.Abdominal pain or tenderness suggestive of peritonitis, 4. Developing de novo or worsening hepatic encephalopathy, 5.Gastrointestinal bleeding within last 15 days, 6. Worsening renal function within last 30 days or Acute renal failure (defined by an increase in the serum creatinine level above 133 micro mol/L) and 7.Arterial hypotension (Systolic BP $<88 \mathrm{~mm}$ of $\mathrm{Hg}$ ).

The clinical presentation of SBP depends on stage at which the infection is diagnosed ${ }^{33}$. In the early stage, most patient are asymptomatic. Patients with SBP are frequently asymptomatic ${ }^{18}$ or have minor symptoms only; this is particularly so when the diagnosis of infection is made at hospital admission. ${ }^{19}$ A clinical diagnosis of infectedascitic fluid without paracentesis is not adequate; the clinician's clinical impression that infection is unlikely does not rule out infection. ${ }^{43}$

So diagnosis of SBP established on the basis of symptoms and signs are not acceptable. ${ }^{19}$ A diagnostic paracentesis should be performed on all hospitalized cirrhotic patient with ascites (whether Symptoms or signs of SBP are present or not) to investigate the presence of SBP. ${ }^{19}$

Because the presentation depends on the stage of the disease and the symptoms and signs are nonspecific, the diagnosis relies on laboratory test.

Currently, paracentesis with laboratory testing of the ascetic fluid is the only way to confirm or rule out SBP in patients with cirrhosis. ${ }^{33}$

The infection of ascetic fluid leads to an elevation of polymorphoneuclear neutrophil (PMN) count in ascetic fluid, which represents evidence of failure of the first line defense, i.e., the peritoneal macrophage, to killing invading organism. Thus elevation of PMN cell count above a certain level in ascetic fluid has been adopted 
as a diagnostic criterion of SBP, without consideration of the detection of bacteria in ascetic fluid cultures (40). In all the available guidelines, diagnosis is based on a fixed defined cut-off PMN cell count in ascitic fluid. ${ }^{44-47}$

On the basis of currently available data, the greatest sensitivity for the diagnosis of SBP is reached with a cut off PMN cell count of $250 / \mathrm{mm}^{3}$, although the greatest specificity is reached with a cut off at 500 $\mathrm{PMN} / \mathrm{mm}^{3}(20,21,22)$. However, since it is important not to miss a case of SBP, the most sensitive cut-off value $\left(\mathrm{PMN}>250 / \mathrm{mm}^{3}\right)$ is used.

In patients with bloody ascitic fluid (i.e. ascitic fluid red blood cell count $>10,000 / \mathrm{mm} 3$, as the result of traumatic tap or conditions causing hemorrhagic ascites (e.g. Neoplasm) ${ }^{23}$, a correction factor of one PMN cell per 250 RBC (red blood cell) has been proposed, since this is the maximum expected ratio of PMN to RBCs normally present in peripheral blood. ${ }^{23}$

The diagnosis of SBP was based upon criteria recommended by the International Ascites Club and published in 2000. ${ }^{10}$ Variants of SBP are: 1.Classical SBP- ascetic fluid PMN cell counts $>250 / \mathrm{mm} 3$ and positive culture. 2. Culture negative neutricitic ascites - ascitic fluid PMN cell counts $>250 / \mathrm{mm} 3$ and negative culture. 3. Bacterascites- a culture positive ascetic fluid in the presence of PMN cell counts $<250 / \mathrm{mm} 3 .{ }^{42}$

Even after pan culturing is properly completed, some series show that $30 \%$ to $40 \%$ of all patients with SBP have negative culture of both blood and ascetic fluid. ${ }^{48}$ Furthermore, these culture methods take at least two to seven days. ${ }^{37,48}$ to produce the desired result. Because of these, when paracentesis is used to obtain an ascitic fluid cytological analysis, remains the single most important test for identifying and assessing a course of SBP. ${ }^{48}$ Unlike the microbiological cultures already mentioned, the paracentesis fluid analysis can be safely performed and can produce valuable results in just one to four hours. ${ }^{43,48}$

Patient with culture negative neutrocytic ascites (CNNA) have similar signs symptoms, and mortality as patients with classical SBP (PMN cell counts $>250 / \mathrm{mm} 3$ and culture positive), and warrant empiric antibiotic treatment. ${ }^{43}$ Delaying treatment until the ascitic fluid culture grows bacteria may result in the death of the patients from overwhelming infection. On the other hand, most patients of bacterascites- $62 \%$ in one studyresolved the colonization without antibiotics and without a neutrophil response. ${ }^{43}$

However, the importance of ascitic fluid culture can't be undermined because apart from giving a definite diagnosis, it also facilitate about the nature of organism and drug most suitable for the treatment.

\section{Materials \& Method}

This study was a cross sectional observational study carried out at the Medicine Wards of Sir Salimullah Medical College and Mitford Hospital, Dhaka over a period of six months from 02/01/2013 to 01/07/2013. Samples were taken by purposive way. A total of 50 cases were enrolled in the study. All adult patients irrespective of sex and ethnic origin with symptoms of decompensated liver cirrhosis, ascites and no sign indicating SBP were included in the study. Patient already on treatment or on prophylaxis for SBP, patients with concomitant intraabdominal infection or other condition which makes the diagnosis of SBP difficult or confusing or patients with ascites not due to chronic liver disease were excluded from the study.A structured questionnaire (research instrument) was developed containing all the variables of interest (Appendix-C). Fifty patients with liver cirrhosis and ascites admitted to different medicine wards of Mitford Hospital over six months period were selected by inclusion and exclusion criteria. The diagnosis of liver cirrhosis was done by clinical, laboratory, ultrasonography and /or histopathologic parameters. The severity of the liver disease was classified in each patient according to the Child Pugh Score. Diagnostic paracentesis was done by standard procedure to those patients who have no clinical features of SBP. Data were collected by interview of the patients / attendants; clinical examination and laboratory investigation (Appendix-C) and their variables are noted below.AASLD recommended standards were followed for diagnostic paracentesis. Paracentesis was performed using blind technique without transabdominal ultrasound guidance. In every case paracentesis was performed using the standard sterile technique to avoid infection. The abdominal wall in left lower quadrant, $3 \mathrm{~cm}$ cephalad and $3 \mathrm{~cm}$ medial to anterior superior iliac spine, has been shown to be thinner and was chosen for needle aspiration. The area of inferior epigastric artery and any visible collateral was avoided. CBC, Liver function test (S.bilirubin, SGPT, SGOT, ALP, Prothrombin time, S. Albumin, S. Globulin, A/G Ratio), USG of whole abdomen, Viral Markers (HBs Ag, Anti HCV, Anti HBcIg), Ascitic Fluid Tap, S.Electrolytes, Endoscopy Upper GIT, Routine urinary examination, S.creatinine, RBS were done in most patients.Informed written consent was taken from the study participants or eligible attendants. Confidentiality of all given information about the patient was ensured.The study did not cause any harm or involve any additional burden to the respondents except their time.Data were processed and analyzed using SPSS (Statistical Package for Social Science) 15.0. Results are presented by choosing of variables 
in the form of tables, graph, percentage, chart etc. The frequency rate of various information were described \& compared using statistical methods. The test statistics were measured by Chi-square (x2) test. The level of significance was set at 0.05 or below.

\section{Observation and Results}

Their age frequency $5(10 \%)$ were from $21-30$ years, $15(30 \%)$ were from $31-40$ years, $15(30 \%)$ were from $40-50 y e a r s$ and $15(30 \%)$ were from $>50$ years of age (Table 1).

Table 1

Frequency of age of participants:

\begin{tabular}{lcc}
\hline Age (years) & Frequency & Percentage \\
\hline$\leq 20$ & 0 & 0 \\
$21-30$ & 5 & 10 \\
$31-40$ & 15 & 30 \\
$41-50$ & 15 & 30 \\
$\geq 50$ & 15 & 30 \\
\hline Total & 50 & 100 \\
\hline
\end{tabular}

Among 50 cases, 38(76\%) were male and 12(24\%) were female (Table II).

Table-II

Frequency of sex of participants:

\begin{tabular}{lcc}
\hline Sex & Frequency & Percentage \\
\hline Male & 38 & 76 \\
Female & 12 & 24 \\
\hline Total & 50 & 100 \\
\hline
\end{tabular}

The etiology of chronic liver disease was hepatitis B virus in $22(44 \%)$, hepatitis C virus in $4(8 \%)$, alcohol in $1(2 \%)$ and others in $23(46 \%)$ patients (Table-III).

Table-III

Etiology of $C L D$

\begin{tabular}{lcc}
\hline Etiology & Frequency & Percentage \\
\hline HBV & 22 & 44 \\
HCV & 4 & 8 \\
Alcohol & 1 & 2 \\
Unknown & 23 & 46 \\
\hline Total & 50 & 100 \\
\hline
\end{tabular}

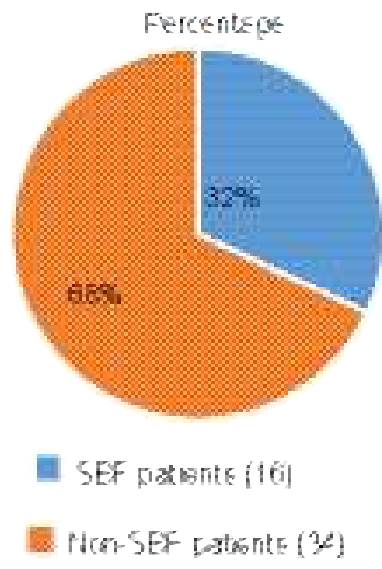

Figure 1: SBP versus Non-SBP patients:

Table-IV

Age range of subjects in $S B P$ and non-SBP groups

\begin{tabular}{llcccc}
\hline Age & $\begin{array}{c}\text { Total } \\
\text { Patients patients }\end{array}$ & $\begin{array}{c}\text { SBP } \\
\text { of SBP } \\
\text { patients }\end{array}$ & $\begin{array}{c}\text { Porcentage } \\
\text { sBP } \\
\text { patients }\end{array}$ & $\begin{array}{c}\text { Percentage } \\
\text { of non- } \\
\text { SBP } \\
\text { patients }\end{array}$ \\
\hline $21-30$ & 5 & 1 & 2 & 4 & 8 \\
$31-40$ & 15 & 3 & 6 & 12 & 24 \\
$41-50$ & 15 & 5 & 10 & 10 & 20 \\
$>50$ & 15 & 7 & 14 & 8 & 16 \\
\hline
\end{tabular}

Table-V

Child-Pugh classification of cirrhosis

\begin{tabular}{lccc}
\hline Factor & 1 & 2 & 3 \\
Encephalopathy & None & Stage & Stage 3 \\
& & $1 \& 2$ & $\& 4$ \\
\hline Ascitis & None & Mild & Marked \\
Bilirubin (mg/dL) & $<2$ & $2-3$ & $>3$ \\
Albumin & $>3.5$ & $3-3.5$ & $<3$ \\
PT prolongation & $<4$ & $4-6$ & $>6$ \\
\hline
\end{tabular}

Add the individual score: $<7=$ Child's A, $7-9=$ Child's B, $>9=$ Child's $C$.

\section{Table-VI}

Grading of patients according to Child Pugh's classification of cirrhosis:

\begin{tabular}{lcc}
\hline & Number of patients & Percentage (\%) \\
\hline Grade B & 18 & $36 \%$ \\
Grade C & 32 & $64 \%$ \\
\hline
\end{tabular}


Role of ascitic fluid study in early detection of spontaneous bacterial peritonitis

BJM Vol. 30 No. 1

Table-VII

Clinical features in two study groups

\begin{tabular}{lccccc}
\hline Clinical features & \multicolumn{2}{c}{ SBP group $(\mathrm{n}=16)$} & \multicolumn{2}{c}{ Non SBP group (34) } & P-Value \\
& No. of Patients & Percentage & No. of patients & Percentage & \\
\hline Upper GIT bleeding & 08 & $50 \%$ & 15 & $44.11 \%$ & 0.10 \\
Hepatic encephalopathy & 09 & $56.25 \%$ & 13 & $38.23 \%$ & 0.30 \\
Jaundice & 10 & $62.50 \%$ & 11 & $32.35 \%$ & 0.66 \\
Splenomegaly & 16 & $100 \%$ & 18 & $52.94 \%$ & 0.22 \\
Ascites & 16 & $100 \%$ & 34 & $100 \%$ & 1.0 \\
Asymptomatic & 05 & $10 \%$ & 00 & 00 & 0.02 \\
\hline
\end{tabular}

Table-VIII

Number \& Percentage of SBP and non SBP patients at Child-Pugh stage:

\begin{tabular}{lccc}
\hline Stage & A & B & C \\
\hline SBP frequency & 2 & 5 & 9 \\
SBP percentage & 12.5 & 31.25 & 45.25 \\
Non-SBP frequency & 14 & 11 & 9 \\
Non-SBP percentage & 41.17 & 32.35 & 26.47 \\
\hline P - values & 0.14 & 0.10 & 0.02 \\
\hline
\end{tabular}

Table-IX

Number \& Percentage of SBP patients according to PMN cell counts

\begin{tabular}{lcc}
\hline $\begin{array}{l}\text { Cell } \\
\text { counts } / \mathrm{mm} 3\end{array}$ & $\begin{array}{c}\text { No. of SBP } \\
\text { patients }\end{array}$ & $\begin{array}{c}\text { Percentage of } \\
\text { SBP patients }\end{array}$ \\
\hline $250-1000$ & 7 & $43.75 \%$ \\
$1000-1750$ & 6 & $37.50 \%$ \\
$>1750$ & 3 & $18.75 \%$ \\
\hline
\end{tabular}

Table-X

Ascitic Fluid Analysis Mean Values Among Two Groups

\begin{tabular}{llccc}
\hline $\begin{array}{l}\text { Serial } \\
\text { no. }\end{array}$ & Contents & SBP & $\begin{array}{c}\text { Non } \\
\text { SBP }\end{array}$ & $\begin{array}{c}\text { P- } \\
\text { values }\end{array}$ \\
\hline 1. & Albumin & $1.08 \mathrm{gm} \%$ & $1.87 \mathrm{gm} \%$ & 0.70 \\
2. & TLC* & $2913 / \mathrm{mm} 3$ & $204 / \mathrm{mm} 3$ & 0.003 \\
3. & PMN Count & $2178 / \mathrm{mm} 3$ & $43 / \mathrm{mm} 3$ & 0.001 \\
\hline
\end{tabular}

*Total Leukocyte Count.

\section{Discussion}

The development of ascites is an important landmark in the natural history of cirrhosis. ${ }^{5,6}$ In most study, ascites was the first complication to occur and to mark decompensation of liver disease, ${ }^{6,7}$ Bacterial infections are a common and recurrent complication of cirrhosis associate with poor outcome. ${ }^{8}$ The most common infections in cirrhotic patients are SBP (25\%), followed by urinary tract infection (20\%), Pneumonia (15\%), bacteraemia following a therapeutic procedure, cellulites. ${ }^{8}$

SBP is a frequent and severe complication of decompansated cirrhosis. Approximately half the episodes of SBP are present at the time of hospital admission and the remainder is acquired during hospitalization. ${ }^{9}$ The percentage of SBP in hospitalized cirrhotic patient with ascites ranges between 10\%$30 \% .10-13$

In most recent prospective study, the mortality rate was reported to be around $20 \% .{ }^{9,14}$ Patients with SBP are frequently asymptomatic ${ }^{18}$ or have minor symptoms only. A clinical diagnosis of infectedascitic fluid without paracentesis is not adequate; the clinician's clinical impression that infection is unlikely does not rule out infection. ${ }^{43}$ So diagnosis of SBP established on the basis of symptoms and signs are not acceptable. ${ }^{19}$

A diagnostic paracentesis should be performed on all hospitalized cirrhotic patient with ascites (whether Symptoms or signs of SBP are present or not) to investigate the presence of SBP. ${ }^{19}$

This study was carried on 50 patients. Among these, $38(76 \%)$ were male and $12(24 \%)$ were female patients (Table II). Their age frequency 5(10\%) were from 21-30 years, $15(30 \%)$ were from $31-40$ years, $15(30 \%)$ were from $40-50$ years, and $15(30 \%)$ were from $>50$ years of age. ${ }^{1}$ 
Zahidullah Khan et al. ${ }^{35}$ studied among 100 study subjects, 52(52\%) were male and 48(48\%) were female. Sayed VA et al. ${ }^{40}$ among 81 eligible patients $48(59.25 \%)$ were males and $33(40.74 \%)$ were females with mean age of $51.1+11.7$ years as $51.34+13.01$ and $49.3+14.06$ amongst males and females respectively. The age of the study population ranged between 23 years to 79 years.

Agarwal et al. ${ }^{36}$ studied on 41 patients, 31 were males and 10 were females and age range was 25 to 70 years.

In this study revealed the etiology of liver cirrhosis was hepatitis B virus in 22(44\%), hepatitis C virus in $4(8 \%)$, alcohol in $1(2 \%)$ and others in $23(46 \%)$ patients (Table III).

Nashaat EH et al. ${ }^{50}$ studied that the etiology of liver cirrhosis was hepatitis $\mathrm{C}$ virus in 35 patients (70\%), hepatitis B in 10 patients $(20 \%)$ and combined hepatitis $\mathrm{C}$ and $\mathrm{B}$ in 5 patients (10\%). El-Sharqawy EH et al. ${ }^{51}$ studied that the causes of liver cirrhosis were: hepatitis $\mathrm{C}$ virus in 33 (73.33\%) and hepatitis B virus in $6(13.33 \%)$ cases. The etiology could not be determined in the remaining 6 patients (13.33\%). These indicate HBV cases are more in our study.

In our study overall frequency of SBP was $32 \%$, this result is slightly higher than some international study $^{10-13}$ that may be due to most patients (56.25\%) of our study at late stage (Child Pugh's C) during presentation who are more prone to develop infection. However this results correlates with some Asian study. A descriptive, cross sectional study was conducted by Zahidullah Khan et al. ${ }^{35}$ in medical units of Khyber Teaching Hospital, Peshawar from July, 2008 to Jan, 2009, have shown that the overall frequency of SBP in cirrhotic patients with ascites was $38 \%$.

MP Agarwal et al. ${ }^{36}$ was conducted a study that shown the prevalence of SBP $34.14 \%$. In this study $46.56 \%$ patients were at Child Pugh's stage C.

Ali Sakib et al. ${ }^{37}$ showed frequency of SBP was $31 \%$ that correlates with further Pakistani study by Imran et al. ${ }^{37}$ (Showed 31.58\%). Ali Sakib et al. ${ }^{37}$ explained the higher prevalence by the late presentation of the patients to the tertiary care hospital in their indigenous set up, advanced stage of disease at presentation, poor socioeconomic condition, under nutrition with weak immune system and noncompliance to the therapy.

Furthermore from India in 1999 Jain A P et al. ${ }^{39}$ showed prevalence of SBP was $34.92 \%$. Syed VA et al. ${ }^{40}$ had prospectively evaluated 81 cirrhotic patients with ascites during one year period and showed prevalence of SBP $24.67 \%$.
$2 \%$ of our SBP patients at age group 21-30 years, $6 \%$ at age group $31-40$ years, $10 \%$ at age group $41-50$ years, and $14 \%$ at age group $>50$ years.

In our study, $50 \%$ of SBP patient's presents with upper UGI bleeding, 56.25\% with hepatic encephalopathy, $62.50 \%$ jaundice, $100 \%$ with splenomegaly and ascites (Table VII).

Symptoms of our SBP patients also correlate with the study results of Ali Sakib et al. ${ }^{37}$ UGI bleeding (51.61\%), jaundice (64.51\%), splenomegaly (83.87\%), ascites (100\%), hepatic encephalopathy (61.29\%), and P-value was $<0.01$, that is same as our study.

But our study result differs with Syed VA et al. ${ }^{40}$ in which most common presenting symptoms were jaundice (95\%), UGI bleeding (75\%),

Our study showed $10 \%$ of SBP patients were totally asymptomatic, that correlate with Ali Sakib et al. ${ }^{37}$ (10\%), Runyon B A ${ }^{53}(10 \%)$ and $Z$. Khan et al. ${ }^{53}$ (10\%) and our frequency of asymptomatic SBP slightly lower than frequency of Tarsila C R Ribero et al.(54) (13\%) and furthermore our frequency is grossly lower than Syed V A et al.(40) (30\%) and Puri A S et al. ${ }^{55}$ (14\%$100 \%)$.

So there is great variation in presenting symptoms and signs of SBP have been reported in different study. In Chinnok B et al. ${ }^{18}$ study, clinical suspicion based on presence of symptoms of SBP in an emergency room setting had a sensitivity of only $76 \%$ and specificity of $34 \%$ for the detection of SBP. This suggested that clinical assessment by itself is an inaccurate for the diagnosis and exclusion of SBP, and led the authors to recommended routine fluid analysis in all patients.

At present study, at the time of presentation $12.5 \%$ of SBP patients at Child Pugh's-A, 31.25\% patients at stage $-B, 56.25 \%$ patients at stage-C (table 8 ). In SBP and non SBP groups $\mathrm{P}$-value of stage-A presentation is 0.14 , stage- $B$ presentation is 0.217 , stage-C presentation is 0.02 . Only stage $-\mathrm{C}$ presentation is significant. In KasztelanSzczerbinska B et al. ${ }^{42} 35.1 \%$ patients at stage- $\mathrm{B}(\mathrm{P}=0.217)$ and $64.9 \%$ at stage- $\mathrm{C}$ $(\mathrm{P}=0.037)$.

As we have not performed ascitic fluid culture and taken PMN cell count $>250 / \mathrm{mm} 3$ as a diagnostic cut off, all of our SBP patients (100\%) have PMN cell count $>250 / \mathrm{mm}$. The ascitic fluids mean TLC counts in patients with non SBP patients quite low as compared to the patients with SBP. Similarly the mean value of ascitic fluid PMN cell count in SBP patients was very high than non SBP patients.

The P-value of PMN cell count and total leukocyte count in two groups is 0.003 and 0.001 respectively that is significant (Table-X). 
This results correlates with the results of Syed V A et al. ${ }^{40}$ (P-value for TLC\&PMN cell was $0.0 \& 0.01$ respectably) and $Z$ khan et al. ${ }^{35}$ (in this study p-value was not shown). In Kasztelan-Szczerbinska B et al, ${ }^{42}$ there was statistically significant difference in the white cell count in two group $(\mathrm{P}=0.03)$.

\section{Limitations}

Ascitic fluid culture was not done in our patients. This study is small size cross sectional observational, so it cannot show the prevalence of asymptomatic SBP. No follow-up investigation could be carried out.

\section{Conclusion}

Ten percent of our study patients were shown high PMN cell counts $(>250 / \mathrm{mm} 3)$ and were asymptomatic. This proportion of asymptomatic SBP is statistically significant. Diagnosis of asymptomatic SBP is possible by analysis of ascitic fluid PMN cell counts and early diagnosis will give the benefit of immediate treatment to improve prognosis.

\section{Recommendations}

Routine ascitic fluid analysis in all patients of decompensated cirrhosis irrespective of their symptoms of SBP is recommended. To remark on the overall prevalence of asymptomatic SBP in cirrhosis with ascites, multicentered large scale study needs to be conducted.

\section{References}

1. Jules L. Dienstag, Chronic Hepatitis. In: Dan L. Longo, Dennis L. Kasper, Anthony S. Fauci, editors. Harrison's Gastroenterology and Hepatology, McGraw Hill, Edition 17th, Chapter 39, Page-390.

2. John P. Iredale and I. Nail Guha; The evolution of Cirrhosis. In: Juan Rodes, Jean Pierre Benhamou, Andres T. Blei, Mario Rizzetto, editors. Text Book of Hepatology, Black Well Publishing. Edition 3rd, Chapter 6, page-583.

3. P Aiden McCormick; Hepatic Cirrhosis. In: James S. Dooley, Anna S. F. Lok, Andrew K. Burroughs, E. Jenny Heathcote, editors. Sherlock's Diseases of the Liver and Biliary System, Wiley-Black well, Edition-12th,Chapter7, page-104 and 108.

4. KimWR,BrownJR,Terrault NA. Burden of liver disease in the united states:Summury of the workshop.Journal of Hepatplogy, 2002;36:227-242. https://doi.org/ 10.1053/jhep.2002.34734 PMid:12085369

5. Gines P,QuinteroE,ArroyoV,Teres J. Compensated cirrhosis: Natural history and prognostic factors. Journal of Hepatology, 1987, 7: 12-18.

6. D Amico G, Morobito A, Pagliaro L. Survival and prognostic indicators in compensated and decompansated cirrhosis. Digestive Diseases and
Sciences: 1986; 31:468-475. https://doi.org/10.1007/ BF01320309

7. Gines P, Quintero E, Arroyo V. Compensated cirrhosis: Natural history and prognostic factor. Journal of Hepatology, 1987; 7:122-8. https://doi.org/10.1002/ hep. 1840070124

8. J Fernandez, M. Navasa, J. Gomez. Bacterial infection in cirrhosis: Epidemiological changes with invasive procedures and norfloxacin prophylaxis, Journal of Hepatology, 2002, vol.35, no.1, pp.140-148. https:// doi.org/10.1053/jhep.2002.30082 PMid:11786970

9. Toledo C,SalmeronJM,RimolaA,NavasaM, ArroyoV,Llach J. Spontaneous Bacterial Peritonitis: Predictive factors of infection resolution and survival in patients treated with cefotaxim;Journal of Hepatology, 1993;17:251-257. https://doi.org/ 10.1002 / hep. 1840170215

10. Caly WR, Strauss E. A prospective study of bacterial infection in patients with cirrhosis. Journal of Hepatology, 1993;18:353-358. https://doi.org/ 10.1016/S0168-8278(05)80280-6

11. Almdal TP, Skinhoj P. Spontaneous bacterial peritonitis in cirrhosis: Incidence, diagnosis and prognosis. Scandinavian Journal of Gastroenterology, 1987; 22:295-300. https://doi.org/10.3109/003655287090 78594

12. Llach J, Rimola A, Navasa M, Gines P, Salmeron JM, Gines A, Arroyo V, Rodes J. Incidence and predictive factors of first episodes of Spontaneous bacterial peritonitis in cirrhosis with ascites: relevance of ascetic fluid protein concentration. Journal of Hepatology, 1992; 16:724-727. https://doi.org/10.1002/ hep. 1840160318

13. Gilbert JA, Kamath PS. SBP: An update, Mayo clinic proceedings. 1995; 75:365-370. https://doi.org/ $10.4065 / 70.4 .365$

14. Lovet JM, Planas R, Morillas R, Quer JC, Cabre E, Boix J, Humbert P, Guilera M, Domenech E, Bertran X. Short time prognosis of cirrhosis with SBP : multivariate study. American Journal of Gastroenterology, 1993; 88:388-392.

15. Ribeiro TC,Chebli JM, Kondo M,Gabburi PD, Chebli LA, FeldnerAC.Spontaneousbacterial peritonitis: How to deal with this life threatening cirrhosis complication? Journal of Therapeutics and clinical risk management. 2008; 4: 919-925.

16. A. Rimola, G.Gracia-Tsao, M.Navasa . "Diagnosis, treatment and prophylaxis of Spontaneous bacterial peritonitis: A Consensus document," Journal of Hepatology, 2000; 32(1): 142-153. https://doi.org/ $10.1016 /$ S0168-8278(00)80201-9

17. Angeloni S, Leboffe C, Parente A, Venditti M, Giordano A, Merli M, Riggio O. Efficacy of current guidelines for the treatment of Spontaneous bacterial peritonitis in the clinical practice. World journal of Gastroenterology, 
2008; 14:2757-2762. https://doi.org/10.3748/ wjg.14.2757 PMid:18461661 PMCid:PMC2709049

18. Chinnock B, Afarin H, Minnigan H. Physician's clinical impression does not rule out Spontaneous bacterial peritonitis in Patients undergoing emergency department paracentesis. Annals of Emergency Medicine 2008; 52:268-73. https://doi.org/10.1016/ j.annemergmed.2008.02.016.PMid:18433932

19. Antoni Rimola, Guadalupe Garcia-Tsao, MiquelNavasa, Laura J.V. Piddock, Ramon Planas, Brigitte Bernard, John M., Inadomi. The international ascites club: Diagnosis, treatment and prophylaxis of Spontaneous bacterial peritonitis. The International Ascites Club, 2002, 14(7): 234-9.

20. Garcia-Tsao G. Spontaneous bacterial peritonitis: Gastroenterology Clinics of North America 1992; 21:257-275. PMid:1568776

21. Bar-Meir A,LernerE, Conn HO. Analysis of ascitic fluid in cirrhosis, American Journal of Digestive Diseases, 1979; 24:136-144.

22. Attali P, Turner K, Pelletier G, Ink O, Etienne JP. Ph of ascitic fluid: diagnosis and prognostic value in cirrhotic and noncirrhotic patients. Journal of Gastroenterology, 1986; 90:1255-1260. https://doi.org/10.1016/00165085(86)90393-8

23. Runyon BA. Ascites and Spontaneous bacterial peritonitis; In: Feldman M, Scharschmidt BF, Sleisenger MH, editor-Sleisenger and Fordtran's Gastrointestinal and Liver disease; Phathophysiology, diagnosis and management, 6th edition,vol2. Philadelphia: W.B. Saunders Co.1998; p1310-1315.

24. Wilson JAP, Suguitan EA, Cassidy WA, Parker RH, Chan $\mathrm{CH}$. Characteristics of ascitic fluid in the alcoholic cirrhotic. Digestive Diseases Science.1979; 24:645648.https://doi.org/10.1007/BF01333710

25. A mini M, Runyon BA. Alcoholic hepatitis 2010: A clinician's guide to diagnosis and therapy. World journal of Gastroenterology2010; 16:4905-4912. https:// doi.org/10.3748/wjg.v16.i39.4905 PMid:20954276 PMCid:PMC2957598

26. Evans LT, Kim R. Poterucha, JJ Kamath, Spontaneous bacterial peritonitis in asymptomatic outpatient with cirrhosis and ascites; Journal of Hepatology, 2003;37:897. https://doi.org/10.1053/jhep.2003. 50119. PMid: 12668984

27. Imran M,HushmiSN,AltafA, RashedH,Hussain T. Spontaneous bacterial peritonitis: Professional medical Journal, 2006; 13(2):201-5.

28. Muhammad Tahir, Muhammad Babar khan, Munir Ahmed: Spontaneous bacterial peritonitis, Pakistan Armed Forced Medical Journal, March, 2007; 25(1):7-9.

29. Todd A.Sheer, Bruce A. Runyon, Spontaneous bacterial peritonitis: Journal of Digestive Diseases, 2005, vol23, no1:32-37.
30. Titol,Rimola A, Gines P, Arroyo V, Rodes J; Recurrence of Spontaneous bacterial peritonitis In cirrhosis: Frequency and Predictive factors; Journal of Hepatology, 1988;8:27-31.https://doi.org/10.1002/ hep. 1840080107

31. Bernard B, Grange J-D, Amiot X, Oplon P, Paynard T; Antibiotic prophylaxis for the prevention of bacterial infection in cirrhotic patient with gastrointestinal bleeding: A meta analysis, Journal of Hepatology, 1999;29:1655-61. https://doi.org/ 10.1002/hep.510290608 PMid:10347104

32. Garcia-Tsao G, Sanyal AJ, Grace ND, Carey W. Prevention and management of Gastrooesophagealvarices and varicealhaemorrhage in cirrhosis. AASLD Practice Guideline. Journal of Hepatology, 2007; 46:922-938. 33. Mansour A. Parsi, AshishAtreja, Nizar N. Zein, SBP: Recent data on incidence and treatment; Cleveland Clinical Journal of Medicine, July, 2004, 71

34. Florin AlexandruCaruntu, LoredanaBenea. SBP: Pathogenesis, Diagnosis, Treatment; Journal of Gastroenterology and Liver Diseases, March 2006, 15(1):51-56.

35. Zahidullah khan, Inamullah Khan, Jamal Ud Din, FazleSubhan, Bughdad Khan, Hamza Khan; Frequency of SBP in Cirrhotic patients with ascites due to HCV and efficacy of ciprofloxacin in its treatment : Gomal Journal of Medical Sciences, July-December 2009, vol. 7, No. 2.

36. MP Agarwal, BR Choudhury, BD Banerjee, Ashwani Kumar; Ascitic fluid examination for diagnosis of SBP in Cirrhotic patients: Journal of Indian Academy of Clinical Medicine, Jan-March2008, Vol 9,No. 1.

37. Ali Sakib, RizwanRasul Khan, ZahidMasood, IrshadulHaque; Frequency of SBP in Cirrhotic patients with ascites due to Hepatitis B and C: Journal of University Medical and Dental College, Jan-Jun 2012, Vol.3, Issue1.

38. Imran M, Hashmi SN, Altaf A, Rashid H and Hussain T. SBP. Professional Med. Journal, June 2006; 13:2015 .

39. Jain AP, CHanra LS and Gupta S. SBP in liver cirrhosis with ascites. Journal of Association of Physicians of India, 1999; 47: 619-21. PMid:10999161

40. Syed VA, Ansari J A, Regmi M, Khanal B. SBP in cirrhotic ascites: A prospective study in tertiary hospitals: Kathmandu University Medical Journal, 2007, vol 5, No. 1, Issue 17,48-59.

41. Jean-Francois cadranel, Jean-Baptiste Nousbaum, Christophe Bessaguet, Pierre Nahon, Richard Moreau, Christine Silvain, Oliver Nouel, Albert Tran :Incidence of SBP in asymptomatic cirrhotic out patients. World Journal of Hepatology; 2013 March 27; 5 (3): 104-108. PMid:23556041 PMCid:PMC3612567 
42. Kasztelan-Szczerbinska B, Slomka M, Serwaki M, Szczerbinska M, Cichoz-Lach H. Prevalence of SBP in asymptomatic in patients with decompensated liver cirrhosis- a pilot study: Advances in Medical Science; 2011, Vol 56(1): 13-17. https://doi.org/10.2478/ v10039-011-0010-6 PMid:21536540

43. AASLD: An update of ascites 2012.

44. Fernandez J, Navasa M, Planas R. Primary prophylaxis of Spontaneous bacterial peritonitis delays Hepatorenal syndrome and improves survival in cirrhosis. Journal of Gastroenterology, 2007, 133:818-24.https:// doi.org/10.1053/j.gastro.2007.06.065.PMid:17854593

45. Grange JD, Roulot D, Pelletier G. Norfloxacin primary prophylaxis of bacterial infections in cirrhotic patients with ascites: a double-blind randomized trial . Journal of Hepatology, 1998;29:430-6. https://doi.org/ 10.1016/S0168-8278(98)80061-5

46. Terg R, FassioE,Guevara M. Ciprofloxacin in primary prophylaxis of Spontaneous bacterial peritonitis: a randomized, placebo-controlled study. Journal of Hepatology , 2008; 48:774-9. https://doi.org/ 10.1016/j.jhep.2008.01.024 PMid:18316137

47. Runyon BA. Management of adult patients with ascites due to cirrhosis: An update. Journal of Hepatology , 2009; 49: 2087-107.https://doi.org/10.1002/ hep. 22853 PMid:19475696

48. Cesar Alaniz, Pharm D, Randholph E. Regal. SBP: A Review of Treatment options; CME credit February 12, 2009, 34(4):7-9.
49. Juan A. Pneda, Manuela Aguilar-Guisado, Antonio Rivera . Natural history of decompansated HCV related cirrhosis in HIV infected patients; Oxford Journals; 2002, vol49; issue 8, pp1274-1282.

50. Nashaat EH, Elaziz HA, Sabry M \& Ibrahim AA. Non endoscopic Predictors of Esophageal Varices and Portal Hypertensive Gastropathy. Nature and Science, 2010, 8 (6):17-19.

51. El-Sharqawy EH, El-Badawy R, Eman M, Fathy EM, Attar IE and Amin H . Assessment of the relation between serum-ascites albumin concentration gradient with esophageal varices and its complication Department of Hepatology, Gastroenterology and Infectious Diseases, Faculty of Medicine, Benha University, Egypt,2009, 13(7):58-63.

52. M R Rajput, B F Zuberi, W M Shaikh, G A Solangi, SM Shaikh, G M Shaikh. Frequency, Microbial spectrum, Clinical and biochemical features of SBP and its variants. Journal of the College of Physician and Surgeons, July 30, 1999, 9(8): 347-350.

53. Runyon BA; SBP; Clinical infectious disease, 1998; 27:669-674.PMid:9798013

54. Tarsila CR Ribero, Julio MF Chebli, Mario kondo, Pedro Duarte Gaburri. SBP: How to deal with this life threatening cirrhosis complication, Therapeutics and Clinical Management 2008, 4(5): 919-925.

55. A S Puri, J Ghoshal. Frequency microbial spectrum, outcome of SBP; Indian Journal of Gastroenterology, 1996; 15(3):86-89.PMid:8926022 